\title{
Childhood Pompe disease: clinical spectrum and genotype in 31 patients
}

\author{
C. I. van Capelle ${ }^{1 \dagger}$, J. C. van der Meijden ${ }^{1 \dagger}$, J. M. P. van den Hout ${ }^{1}$, J. Jaeken², M. Baethmann ${ }^{3}$, T. Voit ${ }^{4}$, M. A. Kroos ${ }^{1}$, \\ T. G. J. Derks ${ }^{5}$, M. E. Rubio-Gozalbo ${ }^{6}$, M. A. Willemsen ${ }^{7}$, R. H. Lachmann ${ }^{8}$, E. Mengel ${ }^{9}$, H. Michelakakis ${ }^{10}$, \\ J. C. de Jongste ${ }^{11}$, A. J. J. Reuser ${ }^{1}$ and A. T. van der Ploeg ${ }^{1 *}$
}

\begin{abstract}
Background: As little information is available on children with non-classic presentations of Pompe disease, we wished to gain knowledge of specific clinical characteristics and genotypes. We included all patients younger than 18 years, who had been evaluated at the Pompe Center in Rotterdam, the Netherlands, between 1975 and 2012, excluding those with the classic-infantile form. None were treated with enzyme replacement therapy at the time of evaluation. We collected information on first symptoms, diagnosis, use of a wheelchair and/or respirator, and enzyme and mutation analysis and assessed muscle strength, pulmonary function, and cardiac parameters.

Results: Thirty-one patients participated. Median age at symptom onset was 2.6 years (range $0.5-13 y$ ) and at diagnosis 4.0 years. Most first problems were delayed motor development and problems related to limb-girdle weakness. Fatigue, persistent diarrhea and problems in raising the head in supine position were other first complaints. Ten patients were asymptomatic at time of diagnosis. Five of them developed symptoms before inclusion in this study. Over 50 \% of all patients had low or absent reflexes, a myopathic face, and scoliosis; $29 \%$ were underweight. Muscle strength of the neck flexors, hip extensors, hip flexors, and shoulder abductors were most frequently reduced. Pulmonary function was decreased in over $48 \%$ of the patients; 2 patients had cardiac hypertrophy. Patients with mutations other than the c.-32-13T > G were overall more severely affected, while 18 out of the 21 patients (86 \%) with the c.-32-13T > G/'null' genotype were male.

Conclusions: Our study shows that Pompe disease can present with severe mobility and respiratory problems during childhood. Pompe disease should be considered in the differential diagnosis of children with less familiar signs such as disproportional weakness of the neck flexors, unexplained fatigue, persistent diarrhea and unexplained high CK/ASAT/ALAT. Disease presentation appears to be different from adult patients. The majority of affected children with GAA genotype c.-32-13T > G/'null' appeared to be male.
\end{abstract}

Keywords: Pompe disease, Childhood, Clinical spectrum, Genotype, Natural course

\section{Background}

Pompe disease, also known as acid maltase deficiency or glycogen storage disease type 2 (OMIM 232300), is a lysosomal storage disorder that presents as a progressive myopathy in which deficiency of the enzyme acid $\alpha$ -

\footnotetext{
* Correspondence: a.vanderploeg@erasmusmc.nl

${ }^{\dagger}$ Equal contributors

${ }^{1}$ Pompe Center and Center for Lysosomal and Metabolic Diseases, Erasmus

MC University Medical Center, Room Sb-1629, P.O. BOX 20603000 CB

Rotterdam, The Netherlands

Full list of author information is available at the end of the article
}

glucosidase (EC 3.2.1.20) causes glycogen to accumulate in lysosomes. Ultimately, this leads to cell destruction [1-3]. In 1932, J.C. Pompe first described the classicinfantile form of the disease [4]. Classic infantile patients characteristically present shortly after birth with generalized and severe muscle weakness and with hypertrophic cardiomyopathy. They do not reach major milestones like walking and usually die within their first year of life $[5,6]$. Later, other forms were reported and Pompe disease appeared to be a continuous spectrum of closely related phenotypes with the classic-infantile form at the most severe end of the spectrum. In the literature, 
milder phenotypes are referred to as childhood, juvenile, adult and late-onset. Patients with these non-classic variants of Pompe disease usually have no hypertrophic cardiomyopathy and present with a more slowly progressive limb-girdle muscle weakness, which eventually results in wheelchair dependency, respirator need, and shortened life expectancy [3, 7-17].

While many publications have described the natural history of the disease in classic-infantile and adult Pompe patients $[5,6,12,14-16]$, there is little information on presenting signs and symptoms in children who do not fulfill the criteria of classic-infantile Pompe disease [18].

To gain knowledge of the presentation of Pompe disease in children and to describe their specific clinical characteristics, we set up an observational study to collect information on disease symptoms, the distribution and severity of muscle weakness, physical limitations, lung function, cardiac structure and function, and genotypes of 31 children diagnosed with a non-classical presentation of Pompe disease.

\section{Methods}

\section{Subjects}

This observational study included all patients under the age of 18 years who had been diagnosed at or referred to the Pompe Center at Erasmus MC University Medical Center between 1975 and 2012. These patients came from the Netherlands and abroad, and had been diagnosed by measurement of the acid $\alpha$-glucosidase activity in cultured fibroblasts, leukocytes or muscle biopsy specimens, and by mutation analysis. Patients with classic-infantile Pompe disease were not included in this study.

Thirty-one patients participated in this cross-sectional study. They were evaluated as part of studies approved by the Institutional Review Board $(n=28)$ or as part of routine clinical evaluation $(n=3)$. Medical history was obtained at first visit. Per patient, the following data were collected: gender, current age, geographic origin, first symptoms, age at first symptoms, age at diagnosis, wheelchair use, respiratory support, specific clinical findings (e.g. facial muscle weakness, bulbar muscle weakness, scoliosis, contractures, or muscle atrophy); functional impairments, spirometry and weight and height. Low body weight was defined as weight corrected for height if under 2SD for peers. Blood tests included measurement of creatine kinase (CK), aspartate aminotransferase (AST), alanine aminotransferase (ALT), and lactate dehydrogenase (LDH). A pediatrician and child neurologist performed clinical and neurological examinations in all patients. Only natural course data were included. None of the patients had been treated with enzyme replacement therapy.

\section{Muscle-strength testing}

Muscle strength was assessed by hand-held dynamometry (HHD) $(n=24)$ and manual muscle-strength testing (MMT) $(n=24)[19,20]$. The following muscle groups were tested with HHD: neck flexors, shoulder abductors, elbow flexors, wrist extensors, hip flexors, hip abductors, knee extensors, knee flexors, and foot dorsal flexors. HHD scores (Newton) were expressed as percentages of the reference values $\left(50^{\text {th }}\right.$ percentile) for healthy peers [20]. All percentages were cumulated and divided by 9 to obtain a total HHD sum score expressed in percentage of normal.

MMT was performed according to the Medical Research Council guidelines [21] for the following muscle groups: neck flexors, neck extensors, deltoid muscles, biceps, triceps, wrist extensors, hip flexors, hip extensors, hip abductors, hip adductors, knee flexors, knee extensors, and foot dorsal and plantar flexors.

\section{Lung function testing}

Lung function testing was performed by spirometry with the patients in upright-seated position $(n=28)$, and supine position $(n=23)$ according to ATS/ERS standards [22]. The highest outcome of three reproducible tests was used for analysis. The results were expressed as percentage of predicted and as a z-score, due to the paradigm shift towards z-scores, based on reference values corrected for age, length, gender and race [23]. A percentage lower than $80 \%$ of predicted and a z-score below -1.64 were considered abnormal. Two patients were too young for reproducible spirometry to be reliable. Because of poor lung function six other patients were unable to perform testing in a supine position and one of them in either sitting or supine position.

\section{Cardiac assessment}

In all patients, conventional Doppler, and 2D M-mode tracings were performed by an experienced sonographer (JP) according to the recommendations of the American Society of Echocardiography (Sonos 5500 ultrasound system, Philips, Best, the Netherlands). Standard 12-lead electrocardiograms were also made and analyzed by a pediatric cardiologist.

\section{Enzymatic and molecular assays}

Acid $\alpha$-glucosidase activity was measured in leukocytes [24] and in cultured skin fibroblasts [13] according to standard procedures, and was expressed in $\mathrm{nmol} / \mathrm{h} / \mathrm{mg}$ protein. The protein concentrations of cell homogenates was measured as described previously [25].

Genomic DNA was isolated from blood or cultured fibroblasts, and mutation analysis of the GAA gene was performed according to standard procedures [13, 26]. The severity of the mutations were rated using the 
format of Kroos et al. [27], and were examined for their effect on enzyme activity, quantity, and quality, in transfected cells after site directed mutagenesis [26]. In case of splice site mutations, the effect of the mutation was examined using real-time PCR in mRNA, isolated from the patients' fibroblasts [27].

\section{Statistics}

Demographic and clinical data were summarized using descriptive statistics including mean, SD, median, ranges, and percentages. As the data were not normally distributed, differences between groups were analyzed using a Mann-Whitney test. $P$-values $<0.05$ were considered statistically significant. All statistical analyses were performed using SPSS for Windows version 21.

\section{Results}

\section{Symptom onset and diagnosis}

Thirty-one children participated in this cross-sectional study. Table 1 shows the patient characteristics and genotype. Twenty-two patients were male, nine were female. There were 17 patients from the Netherlands, 4 from Belgium, 5 from Germany, 3 from Greece, 1 from Great Britain, and 1 from the United States.

The median age at which patients had experienced their first symptom was 2.6 years (range $0.5-13 y$ ). At time of diagnosis, their median age was 4.0 years (range $0-16 y)$. The commonest presenting symptoms were delayed motor development (in nine patients), and other symptoms related to limb-girdle weakness, such as frequent falling, difficulty climbing stairs, and problems with running and sports. Fatigue, persistent diarrhea and problems in raising the head in supine position were other first complaints. Median time span between symptom onset and diagnosis was 0.9 years (range 0 to 5.8 years).

Ten patients had been diagnosed pre-symptomatically. In six of them the diagnosis was made after elevated CK and transaminase serum levels had been found during a hospital admission for unrelated matters. The other four patients had been diagnosed because they had a sibling with Pompe disease. Five of these ten patients developed symptoms between diagnosis and first examination in our hospital (see for details Table 1).

\section{Clinical findings}

All 31 patients were evaluated in the Pompe Center at Erasmus MC University Medical Center. Their ages at the time of examination ranged from 0.1 to 17.1 years. Table 2 shows the findings on clinical examination. Over $50 \%$ of the 31 patients had low or absent reflexes, a myopathic face, and scoliosis. Facial muscle weakness was generally mild and did not lead to speech difficulties or dysphagia. One exception was a patient (patient 23 in
Table 1) that had severe dysarthria and was fed via a percutaneous endoscopic gastrostomy catheter. This patient had been wheelchair bound and ventilator dependent since the age of 6 years.

Nine patients had flexion contractures, mainly in the ankles. Three of the nine patients had contractures of the hips and knees. Several patients had undergone corrective surgery for either contractures $(n=4$, patients 1 , 6, 10, 29 in Table 1$)$, or scoliosis $(n=4$, patients 7,14 , 23, 30 in Table 1). It is noteworthy that $29 \%$ of the patients were underweight; corrected for height, their weight was 4.3 to 2.0 standard deviations below healthy peers.

Standardized neurological examination of all patients showed that $70 \%$ had one or more physical limitations. Over $50 \%$ of all patients had difficulties standing up from supine position and flexing the neck in supine position (Table 2). Other important limitations were problems with climbing stairs, rising from a chair and standing up from sitting on their heels.

\section{Distribution of muscle weakness}

Figure 1 shows the severity of muscle weakness and in how many patients the various muscle groups were affected. The commonest weakness was in the neck flexors, which were affected in $75 \%$ of the patients. Other muscles that were frequently affected were the gluteus maximus (extension of the hip), the ileopsoas (flexion of the hip), the biceps and the deltoid muscle. The triceps, wrist extensors, and foot plantar flexors were relatively unaffected. In patients with far advanced disease, all muscles were affected.

All patients had a lower total HHD sum score than age related peers. Total muscle strength ranged from 0 $79 \%$ of normal (median $55 \%$ ). Four patients were wheelchair-bound at the time of investigation; four others became wheelchair dependent in the period thereafter. The ages of these eight patients when they became wheelchair dependent ranged from 4 to 22 years ( $n=8$, median 7.5 years). The median time period between first symptoms and loss of ambulation was 4.5 years ( $n=8$, range 3 to 15 years).

\section{Lung function testing}

In all subjects, FVC values were equal or higher than slow VC. Hence, all analyses were done on FVC. In sitting position, 14 of the 29 patients ( $48 \%$ ) had decreased forced vital capacity (FVC) indicated by z-score below -1.64 (13 patients had a percentage of predicted below $80 \%)$. In one of these patient the FVC was too low to be measured reliably in sitting position. In supine position, 19 of the 29 (66 \%) had a FVC z-score below -1.64 (18 patients had a percentage of predicted below $80 \%$ ). In 6 of these patients, lung volume was too low to be 
Table 1 Patient characteristics

\begin{tabular}{|c|c|c|c|c|c|c|c|c|c|c|c|c|c|}
\hline Pt & Sex & Onset $(y)^{9}$ & $\begin{array}{l}\text { Diagnosis } \\
(y)^{g}\end{array}$ & $\begin{array}{l}\text { Examination } \\
(y)^{g}\end{array}$ & $\begin{array}{l}\text { Wheelchair } \\
\text { (y) }\end{array}$ & Ventilator (y) & $\begin{array}{l}\text { FVC } z \text {-score sitting } \\
\text { (\% pred) }\end{array}$ & $\begin{array}{l}\text { FVC z-score su- } \\
\text { pine (\% pred) }\end{array}$ & $\begin{array}{l}\text { MRC } \\
\%\end{array}$ & $\mathrm{CK} U / \mathrm{I}$ & $\begin{array}{l}\text { GAA activity } \\
(\mathrm{nmol} / \mathrm{h} / \mathrm{mg})^{h}\end{array}$ & Allele 1 & Allele 2 \\
\hline $1^{a}$ & M & 0.5 & 2.5 & 10.04 & Yes (11) & No & $-0.25(97 \%)$ & $-1.12(87 \%)$ & $65 \%$ & 530 & 9.1 & c.-32-13T > G (pm) & c.525delT (vs) \\
\hline $2^{e, f}$ & $\mathrm{~F}$ & 0.8 & 0 & 0.1 & No & No & Too young & Too young & n.a. & 358 & Deficient & c.-32-13T > G (pm) & C.2135 T > C (Is) \\
\hline 3 & $\mathrm{~F}$ & 0.8 & 1.1 & 8.9 & No & No & $0.21(102 \%)$ & $0.1(101 \%)$ & $89 \%$ & 1871 & 13.3 & c. $-32-13 T$ > G (pm) & c.923A > C (pls) \\
\hline $4^{e}$ & M & 0.8 & 2 & 2.4 & No & No & Too young & Too young & n.a. & 1353 & 13 & c.-32-13T > G (pm) & c. 2135 T > C (Is) \\
\hline 5 & M & 0.8 & 2.3 & 9.5 & No & No & $-1.53(82 \%)$ & $-1.71(80 \%)$ & $98 \%$ & 550 & 15.4 & c. $-32-13 \mathrm{~T}>\mathrm{G}(\mathrm{pm})$ & c.525delT (vs) \\
\hline 6 & M & 1 & 2 & 8.2 & Partially (4) & No & $-3.47(59 \%)$ & $-4.36(48 \%)$ & $79 \%$ & 3078 & 4.5 & c. $-32-13 \mathrm{~T}>\mathrm{G}(\mathrm{pm})$ & c.1051delG (vs) \\
\hline 7 & M & 1 & 2 & 13.7 & No & At night (12) & $-4.08(54 \%)$ & $-5.4(39 \%)$ & $87 \%$ & 548 & 17.9 & c.-32-13T > G (pm) & c.525delT (vs) \\
\hline 8 & M & 1.5 & 2 & 13.3 & No & No & $-0.91(90 \%)$ & $-1.76(80 \%)$ & $93 \%$ & 1595 & 16 & c.-32-13T > G (pm) & $\begin{array}{l}\text { c.2481+ 102_2646 } \\
+31 \text { del (vs) }\end{array}$ \\
\hline $9^{a, f}$ & M & 2 & 1 & 6.6 & No & No & $-0.97(89 \%)$ & $-1.4(84 \%)$ & $94 \%$ & 763 & 11 & c.-32-13T > G (pm) & c.525delT (vs) \\
\hline 10 & M & 2.5 & 3 & 13 & No & No & $-3.01(66 \%)$ & $-4.09(54 \%)$ & $84 \%$ & 1960 & 8.6 & c.-32-13T > G (pm) & $\mathrm{c} .2331+2 \mathrm{~T}>\mathrm{A}(\mathrm{vs})$ \\
\hline $11^{d}$ & M & 5 & 10.8 & 10.8 & No & No & $0.2(102 \%)$ & $-0.29(97 \%)$ & $97 \%$ & 588 & 11.9 & c.-32-13T > G (pm) & c.525delT (vs) \\
\hline 12 & $\mathrm{~F}$ & 5 & 7.8 & 7.8 & No & No & $0.62(108 \%)$ & $0.35(104 \%)$ & $100 \%$ & 1003 & 11.6 & c. $-32-13 \mathrm{~T}>\mathrm{G}(\mathrm{pm})$ & $c .2331+2 \mathrm{~T}>\mathrm{A}$ (vs) \\
\hline $13^{f}$ & M & 5 & 2 & 7.6 & No & At night (5) & $-1.77(78 \%)$ & $-1.72(79 \%)$ & $100 \%$ & 436 & Deficient & c. $-32-13 \mathrm{~T}$ > G (pm) & c. $1062 C>$ G (pls) \\
\hline 14 & M & 7 & 10 & 10.7 & Yes (22) & At night (16) & $-2.22(75 \%)$ & Unable & $80 \%$ & 540 & 8,9 & c.-32-13T > G (pm) & c.1548G > A (pls) \\
\hline $15^{f}$ & M & 8 & 4 & 15.8 & No & No & $-2.65(70 \%)$ & $-3.05(65 \%)$ & $93 \%$ & 1424 & 7.8 & c.-32-13T > G (pm) & c.1441 T > C (pls) \\
\hline $16^{f}$ & M & 12 & 8 & 14.6 & No & No & $-2.43(71 \%)$ & Unable & $82 \%$ & 1808 & Deficient & c.-32-13T > G (pm) & $\begin{array}{l}\text { c. } 307 \mathrm{~T}>\mathrm{G}+ \\
\text { c. } 271 \mathrm{G}>\mathrm{A} \text { (pls) }\end{array}$ \\
\hline 17 & M & 13 & 14 & 14.3 & No & No & $-1.68(81 \%)$ & $-1.77(80 \%)$ & $95 \%$ & 2935 & 6.2 & c. $-32-13 \mathrm{~T}>\mathrm{G}(\mathrm{pm})$ & c.1933G > A (pls) \\
\hline $18^{f}$ & M & no symptoms & 4 & 5.2 & No & No & $-1.41(82 \%)$ & $-1.96(76 \%)$ & $97 \%$ & 677 & Deficient & c.-32-13T > G (pm) & $\begin{array}{l}\text { c.2481+ 102_2646 } \\
+31 \text { del (vs) }\end{array}$ \\
\hline $19^{d, f}$ & M & no symptoms & 13.1 & 13.1 & No & No & $-0.69(92 \%)$ & $-1.77(80 \%)$ & $100 \%$ & 614 & Deficient & c. $-32-13 \mathrm{~T}>\mathrm{G}(\mathrm{pm})$ & c.525delT (vs) \\
\hline $20^{c, f}$ & M & no symptoms & 14 & 15.2 & No & No & $3(135 \%)$ & $1.72(120 \%)$ & n.a. & 1409 & Deficient & c. $-32-13 \mathrm{~T}>\mathrm{G}(\mathrm{pm})$ & c.307 T > G (pls) \\
\hline $21^{c, f}$ & M & no symptoms & 16 & 17.1 & No & No & $1.29(115 \%)$ & $-0.25(97 \%)$ & n.a. & 1506 & Deficient & c.-32-13T > G (pm) & c.307 T > G (pls) \\
\hline 22 & M & 0.5 & 1 & 1.3 & Yes (4) & Died $(10)^{i}$ & $-4.77(45 \%)^{j}$ & Unable & n.a. & 586 & Deficient & C.1798C > T (Is) & c.525delT (vs) \\
\hline 23 & F & 1 & 1.9 & 12.5 & Yes (6) & Yes (6) & Ventilator & Ventilator & $10 \%$ & 1381 & Deficient & $c .875 A>G(p m)$ & unknown/r.0? \\
\hline 24 & M & 2 & 2.9 & 2.9 & Yes (6) & Died $(6)^{i}$ & $-5.29(33 \%)^{j}$ & Unable & n.a. & 1046 & Deficient & unknown & c. $1645 G$ > A (pm) \\
\hline 25 & M & 2.7 & 3.5 & 5.9 & No & No & $0.34(104 \%)$ & $0.04(100 \%)$ & $87 \%$ & 908 & 2.8 & C.1634C > T (Is) & $\begin{array}{l}\text { c.2481+102_2646 } \\
+31 \text { del (vs) }\end{array}$ \\
\hline $26^{b}$ & $\mathrm{~F}$ & 4 & 4 & 8.1 & No & No & $0.01(100 \%)$ & $-0.63(92 \%)$ & $98 \%$ & 572 & 2.3 & c. $-32-3 C>G(\mid s)$ & c. $1551+1 G>A(v s)$ \\
\hline
\end{tabular}


Table 1 Patient characteristics (Continued)

\begin{tabular}{|c|c|c|c|c|c|c|c|c|c|c|c|c|c|}
\hline $27^{b}$ & $M$ & 5 & 5 & 10.1 & No & No & $-1.38(84 \%)$ & $-2.55(71 \%)$ & n.a. & 774 & 1.7 & c. $-32-3 C>G(\mid s)$ & c. $1551+1 G>A$ (vs) \\
\hline 28 & $\mathrm{~F}$ & 6 & 7 & 9.9 & Partially (9) & At night (8) & $-6.36(30 \%)$ & $-6.88(25 \%)$ & $82 \%$ & 979 & 0.3 & C. $1829 C>T(I s)$ & c.1912G > T (pls) \\
\hline 29 & $\mathrm{~F}$ & 6.5 & 11.6 & 12.7 & No & No & $-2.36(73 \%)$ & $-2.89(67 \%)$ & $79 \%$ & 776 & 8.4 & unknown (r.spl 2 \%) & c.525delT (vs) \\
\hline 30 & $\mathrm{~F}$ & 10 & 11 & 16.4 & Yes (16) & Yes (12) & $-8.07(13 \%)$ & Unable & $72 \%$ & 1560 & 3.4 & c. $-32-3 C>A(I s)$ & $\begin{array}{l}\mathrm{c} .877 \mathrm{G}>\mathrm{S}+ \\
\mathrm{c.} 271 \mathrm{G}>\mathrm{A} \text { (pls) }\end{array}$ \\
\hline $31^{f}$ & $F$ & no symptoms & 15 & 15.9 & No & No & $1.33(116 \%)$ & $1.2(115 \%)$ & $100 \%$ & 1040 & 2.5 & $\begin{array}{l}\text { C.861C }>\text { T }(\text { r.spl }= \\
<5 \%)\end{array}$ & c.925G > A (pls) \\
\hline
\end{tabular}

Patients are listed by age of onset and are subdivided into two groups: those who carry the c.-32-13T > G mutation and those who do not ${ }^{\mathrm{a}, \mathrm{b}, \mathrm{c}, \mathrm{d}, \mathrm{e}}$ : Siblings; ${ }^{\mathrm{f}}$ patients who were diagnosed pre-symptomatically; ${ }^{9}$ : Age at onset, age at diagnosis, age at examination expressed in years $(y){ }^{h}{ }^{h}$ : GAA activity was deficient in all patients. Only results obtained in cultured fibroblasts and performed with the same method at Erasmus $\mathrm{MC}$ are reported; i: both patients died of respiratory failure, one at age 6 , the other at age 10 ; ${ }^{j}$. first available lung function measurement (patient still untreated) at the ages of respectively 9 and 5.7 years; severity of the mutation is indicated by (vs) very severe; (pls) potentially less severe; (ls) less severe; (pm) potentially mild (for more information, see www.pompecenter.nl) 
Table 2 Results of clinical and neurological examination

\begin{tabular}{ll}
\hline & Number of patients (Total 31) \\
\hline Clinical findings & $22(71 \%)$ \\
Low/absent reflexes & $16(52 \%)$ \\
Weakness facial muscles & $16(52 \%)$ \\
Muscle tone decreased & $13(42 \%)$ \\
Scapular winging & $12(39 \%)$ \\
Muscle atrophy & $11(35 \%)$ \\
Contractures & $9(29 \%)$ \\
Low body weight & $9(29 \%)$ \\
Ptosis & $0(0 \%)$ \\
Physical limitations & $18(58 \%)$ \\
Standing up from supine position & $17(55 \%)$ \\
Flexing the neck in supine position & $13(42 \%)$ \\
Standing up from sitting on heels & $13(42 \%)$ \\
Climbing stairs & $10(32 \%)$ \\
Rising from a chair & $8(26 \%)$ \\
Erecting back in prone position &
\end{tabular}

Four deep tendon reflexes were tested: the biceps reflex, the triceps reflex, the knee-jerk reflex, and the ankle-jerk reflex

measured reliably in supine position. Lung function measurements are displayed in $\mathrm{z}$-scores and percentage of predicted in Fig. 2. FEV1/VC ratios were normal in all patients, indicative of a restrictive abnormality.

The median difference in FVC between sitting and supine positions (postural drop) was $6.0 \%$ (range 0 to $-18 \%)$. Five patients were ventilator dependent at the time of first evaluation, and one became ventilator dependent during follow-up (see Table 1 for details). Five of these six patients had a scoliosis. At the ages of 6 and 10 years, two other patients died from respiratory failure, when it was decided not to start respiratory support. The median duration from first symptoms to any kind of respiratory support or death by respiratory insufficiency was 4.5 years (range 0 to 11 years, $n=8$ ). The median age at start of ventilation or death was 9 years (range 5 to 16 years, $n=8$ ).

\section{Cardiac evaluation}

Cardiac evaluation showed abnormalities in six patients; in three, the findings were considered to be related to Pompe disease. Two patients had hypertrophic cardiomyopathy without outflow-tract obstruction (patients 22, 23 in Table 1). In one patient, this had first been noticed at one year of age, and in the other at two. Their ECGs showed high amplitude QRS complexes and repolarization disturbances consistent with their hypertrophic cardiomyopathy. In addition, their ECGs and that of a third patient (patient 3 in Table 1) showed a short PR interval and a delta wave suggestive of WolffParkinson-White syndrome.

Minor abnormalities of the cardiac valves were noted in three patients. The abnormalities included a quadricuspid aortic valve, a minor deformity of the tricuspid valve leading to minimal tricuspid regurgitation, and minimal insufficiency of both atrioventricular valves. These abnormalities were all considered to be coincidental findings and not related to Pompe disease.

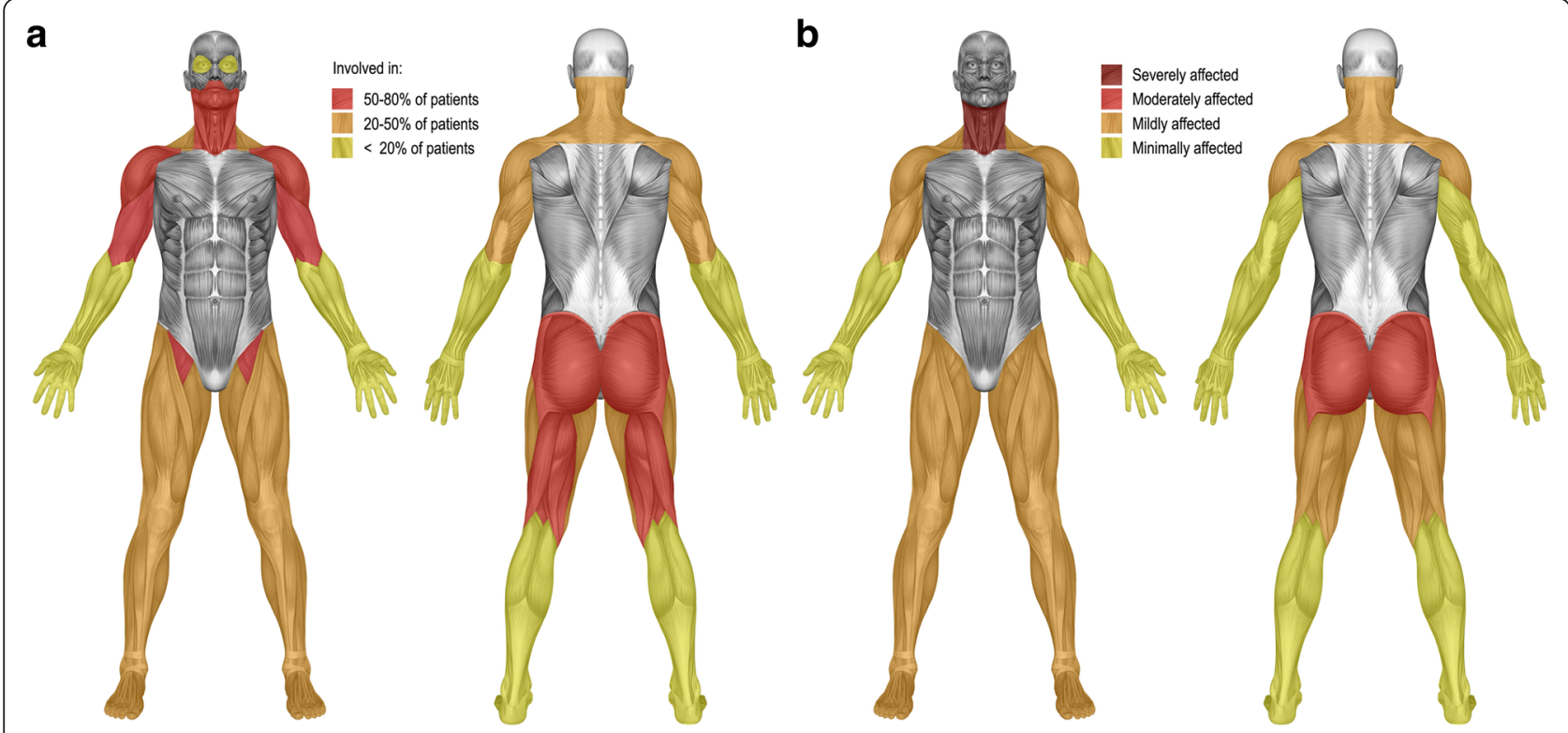

Fig. 1 Distribution of skeletal muscle weakness (a) and severity of weakness of the individual muscles (b) 

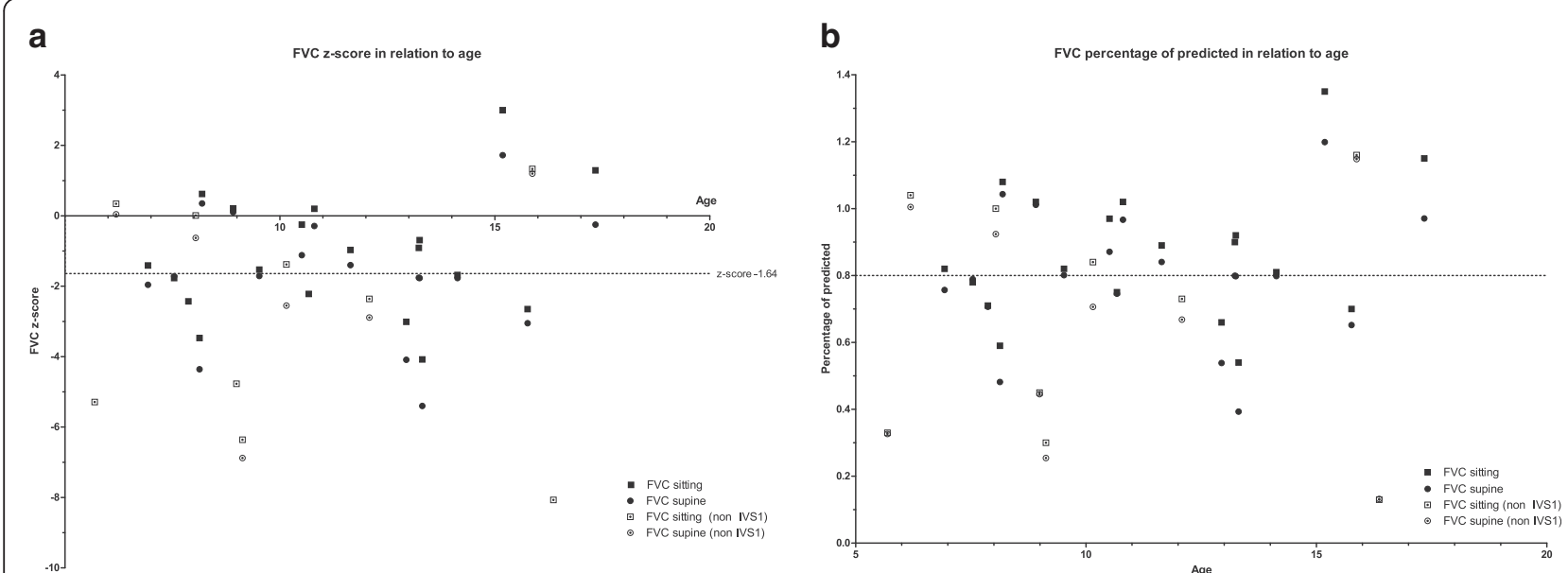

Fig. 2 FVC z-score (a) and percentage of predicted (b) in sitting and supine position

\section{Enzymatic and molecular diagnosis}

Table 1 shows the patients' genotypes and the severity of their mutations. All mutations have been described previously in the literature (www.pompecenter.nl). Twentythree patients $(74 \%)$ carried a potentially mild mutation on one GAA allele and a severe mutation on the other. Twenty-one of these patients carried the common c.32-13T > G splice-site mutation. Since none of the mutations in the other eight patients were considered potentially mild, these patients' genotypes were considered to be more severe. Acid $\alpha$-glucosidase activity measured in cultured fibroblasts ranged from 0.3 to $17.9 \mathrm{nmol} / \mathrm{h} /$ $\mathrm{mg}$ protein $(n=21$, median $=8.6$; control range $45-$ $160 \mathrm{nmol} / \mathrm{h} / \mathrm{mg}$ ). In patients with the c.-32-13T > G/ 'null' genotype activity ranged from 4.5 to $17.9 \mathrm{nmol} / \mathrm{h} /$ $\mathrm{mg}(n=14$, median $=11.3)$ and from 0.3 to $8.4 \mathrm{nmol} / \mathrm{h} /$ $\mathrm{mg}(n=7$, median $=2.5)$ in patients with the non-IVS1 genotype.

\section{Laboratory parameters}

At first visit, all patients had elevated CK levels (median $979 \mathrm{U} / \mathrm{l}$, range 358 to $3078 \mathrm{U} / \mathrm{l}$; normal values below 230 $\mathrm{U} / \mathrm{l})$ ). Transaminase levels were elevated in all 31 patients as well, including those who were symptom-free; AST ranged from 82 to $610 \mathrm{U} / 1$ (normal values below $51 \mathrm{U} / \mathrm{l}$ ), ALT from 71-551 U/l (normal values below 39 U/l). LDH levels were elevated in 21 out of 30 patients, ranging from 449 to $2828 \mathrm{U} / \mathrm{l}$ (normal values below $765 \mathrm{U} / \mathrm{l}$ ).

\section{Comparison of patients with the c.-32-13T > G/'null' genotype (IVS1) and those with other genotypes (non-IVS1)}

Comparison of the twenty-one patients with the c.-32$13 \mathrm{~T}>\mathrm{G} /$ 'null' genotype and the 10 patients with other mutations showed no significant differences in age at first symptoms and age at diagnosis (Table 3 ). Their median age at first examination was similar. We noted that patients in the non-IVS1 group tended to have lower muscle strength and a more severely restricted lung function in sitting and supine positions than those in the IVS1 group. This was in line with the fact that more non-IVS1 than IVS1 patients had become wheelchair bound and ventilator dependent at a relatively young age. In addition, the two patients with hypertrophic cardiomyopathy belonged to the non-IVS1 group. Another interesting observation was that 18 out of the 21 patients $(86 \%)$ with the c. $-32-$ $13 \mathrm{~T}>\mathrm{G} /$ 'null' genotype were male, against 4 out of 10 in the non-IVS1 group. Other than the possible trend that patients with the c.-32-13T > G/'null' genotype were generally less severely affected compared to patients with other genotypes we weren't able to identify other genotype - phenotype relations in the c.-32-13T > G/'null' genotype group.

\section{Discussion}

As little information is available on the clinical presentation of children with non-classic forms of Pompe disease, we evaluated 31 children's clinical and molecular characteristics. Our findings highlight that non-classic Pompe disease can cause a significant burden in childhood and add to the understanding that Pompe disease presents as a broad spectrum of clinical phenotypes.

The presentation of Pompe disease can be variable. Children in our patient population typically presented with weakness of the limb-girdle muscles and/or delayed motor development; lung function was compromised in approximately half of them, and 2 patients whose muscle function deteriorated very rapid also had hypertrophic cardiomyopathy.

Nevertheless, the diagnosis of Pompe disease should also be considered in children whose symptoms are less typical, such as disproportional weakness of the neck 
Table 3 Comparison of patients with the c.-32-13T > G mutation and other mutations at the time of examination

\begin{tabular}{|c|c|c|c|c|}
\hline & All & c. $-32-13 T>G$ & Other mutations & $P$-value \\
\hline Patients & 31 & 21 & 10 & - \\
\hline$M / F$ & $22 / 9$ & $18 / 3$ & $4 / 6$ & \\
\hline Age first symptom (median) & $2.6(0.5-13)$ & $2(0.5-13)$ & $4.0(0.5-10)$ & 0.6 \\
\hline Age diagnosis (median) & $4.0(0-16)$ & $3.0(0-16)$ & $4.5(1-15)$ & 0.6 \\
\hline Age at examination (median) & $10.1(0.1-17.1)$ & $10.7(0.1-17.1)$ & $10(1.3-16.4)$ & 0.7 \\
\hline Disease duration (median) & $5.1(0.8-12.7)$ & $6.5(1.3-12.7)$ & $4.1(0.8-11.5)$ & 0.2 \\
\hline Diagnosed pre-symptom. & 10 & 9 & 1 & - \\
\hline Still symptom free & 5 & 4 & 1 & - \\
\hline HHD sumscore (\%) & $55(n=24)$ & $58(n=18)$ & $36(n=6)$ & 0.02 \\
\hline FVC pred sitting (\%) ${ }^{a}$ & 82 & 82 & 58 & 0.15 \\
\hline FVC pred supine (\%) ${ }^{a}$ & 79 & 80 & 55 & 0.08 \\
\hline
\end{tabular}

Disease duration is calculated as time between the presentation of first symptoms and first examination in our hospital

${ }^{a}$ For patients who didn't perform lung function testing in supine position the value obtained in sitting position was used. For one patient using $24 \mathrm{~h}$ invasive ventilation a value of $0 \%$ was used in the analyses

flexors, unexplained fatigue, persistent diarrhea, and an elevation of transaminase levels. Independent of whether the children had symptoms or not, all patients participating in the study had elevated CK, ALT and AST values. It should be noted, however, that in rare cases CK, ALT and AST may be normal, as we very recently encountered in a childhood onset patient (personal communication) and as was earlier described for about $10 \%$ of adult patients [28].

Although respiratory problems did not precede proximal muscle weakness in any of the children, lung function was already significantly restricted in $48 \%$ of the cases. In $26 \%$ of the affected children, respiratory insufficiency either led to the need for ventilator support or resulted in death during childhood. This finding signifies the importance of early monitoring of lung volume by means of spirometry in children affected by Pompe disease as also advised in adults $[17,29]$.

Lung function tests are best performed in both sitting and supine positions, as 9 patients had postural drops suggestive of diaphragm weakness. This is a well-known feature of Pompe disease, and contributes to the onset of nocturnal hypoventilation $[29,30]$. Since a recent study in children with neuromuscular disorders found that daytime lung function and nocturnal hypoxemia were poorly correlated, we suggest to regularly perform sleep studies as an additional tool for identifying children with nocturnal hypoventilation [31].

Twenty-two of the 31 children that we investigated were male. Interestingly, among them were 18 with the c.-32-13T > G/'null' genotype that is most common among adult patients (against only 3 of the 9 female patients). In two studies that focused on disease variation among children and adults with the c.-32-13T > G/'null' genotype, the male-to-female distribution was equal (55 and $58 \%$ males, respectively). However, neither study focused on any potential difference in age at onset between male and female patients [12, 13]. The present study indicates the existence of such a gender difference. Our earlier analysis of 225 published case reports on children and adults with Pompe disease also showed a predominance of males (67 \%) in patients under 18 years old [11]. Previous studies reported that pulmonary function was more affected in males than in females [17], and that more men than women had bulbar involvement and shoulder-girdle muscle weakness [17]. A study comparing phenotypes in siblings with Pompe disease also confirmed that males were more severely affected than females [32].

Since Pompe disease is inherited as an autosomal recessive trait, there has been no satisfactory explanation to date why males with the same GAA genotype as females would present at an earlier age. This finding seems to suggest that the clinical expression of Pompe disease involves secondary gender-related factors. Gender differences have also been reported for other neuromuscular disorders such as facioscapulohumeral muscular dystrophy and some subtypes of limb-girdle muscular dystrophy [33-35]. One muscle related difference between men and women found so far is that women with limb girdle muscular dystrophy type $2 \mathrm{~A}$ and $2 \mathrm{~B}$ showed less muscle fiber atrophy compared to males [35]. This may also apply in Pompe disease. Though other causes have been suggested, such as differences in genetic and epigenetic factors, the exact mechanism remains elusive.

Our findings are fully consistent with the broad spectrum of clinical phenotypes associated with the c.-32-13T > G/ 'null' GAA genotype [12, 13]. Looking at the genotypephenotype correlation within our group of children shows a similar age of onset, age at diagnosis, and current age for all different genotypes. Several patients were wheelchair 
bound and/or ventilator dependent despite of having the c.-32-13T > G/'null' genotype, which is mostly associated with adult onset disease. The c.-32-13T > G, is a leaky splice site mutation that results in the formation of 10$20 \%$ of normally processed alpha-glucosidase protein and activity, which explains the later onset non-classic phenotype in patients c.-32-13T > G/'null' genotype. In our group of patients the second mutation (severe, less severe or potentially less severe) did not seem to have an effect on the age of presentation. This is in line with earlier studies of Kroos et. al., Wens et.al. and Montalvo et. al. also showing a broad variation of phenotypes among patients with the c.-32-13T > G/null genotype. It was hypothesized that epigenetic factors and environmental factors influence the level of disease severity [12, 13, 32]. More research is required.

At a group level, children in the non-IVS1 group seem to be more severely affected than patients with the 32-13T $>$ G/'null' genotype. This is illustrated by two specific patients in the non-IVS1 group who had hypertrophic cardiomyopathy and became fully wheelchair bound; one at the age of 4 years and the other at the age of 6 . The first child died from respiratory failure at the age of 10. The other child became completely ventilator dependent when she was 6 years old. These two patients expressed a phenotype that Slonim et al. previously called the "atypical infantile form" of Pompe disease [18].

Overall, the genotypes identified in the non-IVS1 group were more severe than those in the IVS1 group (see Table 1 and www.pompecenter.nl). Some of the genotypes have been described in the literature, such as the genotype c.1634C > T/c.2481+102_2646+31del (our patient 25). The c.1634C $>\mathrm{T}$ (ls) in combination with a very severe mutation was previously described in three patients. One of those patients presented at the age of one year, became dependent on respiratory support at the age of 20, and was wheelchair bound at the age of 23 [15]. The second patient was diagnosed at 16 years of age, and began to use a walking stick at 19 . Pulmonary function worsened at the age of 17-19 years and vital capacity dropped to $26 \%$ of predicted and became respirator dependent at the age of 20 years [36]. The third patient presented at the age of 13 years with pronounced limb girdle weakness and died at the age of 18 years [37]. The similarities in clinical course of these previously reported cases are remarkable, and if the genotype-phenotype correlation holds for our patient, who was only 6 years old at time of examination, he carries a high probability to develop severe respiratory and mobility problems before adulthood. Such information may be relevant when it is time to decide when to start enzyme replacement therapy.

Children and adults share a wide variation of disease presentation and disease progression, and a similar involvement of respiratory and proximal skeletal muscles $[8,9,12-16]$. Although the distribution of muscle weakness shows a limb-girdle pattern in both children and adults, there are also differences. While the neck flexors are by far the most severely affected muscle group in children, they are only mildly affected in adults $[8,15]$. A recent MRI study performed in 20 adult patients by Carlier et al. also showed relatively mild involvement of the neck flexors in adults [38].

Another difference is the relative sparing of the quadriceps muscle in adult patients [28, 38]. In the current population of 31 children with Pompe disease, the muscles of the thigh were affected more heterogeneously, and the quadriceps muscles were not spared. Neither did any of our patients have ptosis, despite a recent publication in which ptosis was present in 14.7 to $23 \%$ of adult Pompe patients [28, 39, 40]. It should be noted that ptosis has often been found in an early stage of the disease, even as a presenting symptom in adult Pompe patients. While van der Beek et al. found that patients had difficulties with speech, chewing or swallowing, which was suggestive of bulbar weakness in $28 \%$ of their patients, we found bulbar weakness in only one patient. In contrast, $52 \%$ of our children had scoliosis, compared to only 21 to $23 \%$ of adult Pompe patients [11, 28]. In several children the scoliosis was so severe that it interfered with their mobility and lung volume; four children needed surgical correction of the spine. A crosssectional analysis of data from the Pompe Registry, a large multinational observational program, found scoliosis to be present in $57 \%$ of patients with childhood disease onset [41].

Our study had two main limitations. First, since the Pompe Center at Erasmus MC University Medical Center serves as a national and international referral center for Pompe disease, there may be selection bias, due to referral of patients who were more than average severely affected. Nonetheless, ten of the 31 patients had been diagnosed pre-symptomatically, 5 of whom were still symptom-free at time of evaluation. A second limitation is the fact that the study was cross-sectional. As all children manifesting significant symptoms of the disease, started to receive enzyme replacement therapy during follow-up, the approval of this therapy in 2006 interfered with the collection of longitudinal follow-up data.

\section{Conclusions}

In conclusion, our study shows that the course of childhood Pompe disease varies widely, and patients may manifest serious problems before adulthood. We stress that Pompe disease should be considered in the differential diagnosis of patients with less familiar signs such as disproportional weakness of the neck flexors, unexplained fatigue and persistent diarrhea. Disease presentation, 
distribution of muscle weakness, and the occurrence of specific symptoms such as bulbar muscle weakness or ptosis all appear to be different from those in adult patients. Regular assessment of lung volume and sleep studies are recommended to identify children at risk for early respiratory insufficiency. Patients with mutations other than the c.-32-13T > G were overall more severely affected, which is consistent with their more severe genotypes. The majority of affected children with GAA genotype c.-32-13T > G/'null' appeared to be male.

\section{Ethics approval and consent to participate}

All procedures followed were in accordance with the ethical standards of the responsible committee on human experimentation (institutional and national) and with the Helsinki Declaration of 1975, as revised in 2000. Informed consent for inclusion in the study was obtained from all patients and/or their parents.

\section{Consent for publication \\ Not applicable}

\section{Availability of data and material}

All available data is published in the manuscript. Individual patient records can't be made available due to patients' privacy.

\begin{abstract}
Abbreviations
ALT: alanine aminotransferase; AST: aspartate aminotransferase; ATS: American thoracic society; CK: creatinine kinase; ERS: European respiratory society; FEV1: forced expiratory volume; FVC: forced vital capacity; GAA: acid a-glucosidase gene; HHD: hand held dynamometry; LDH: lactate dehydrogenase; MMT: manual muscle testing; VC: vital capacity.
\end{abstract}

\section{Competing interests}

Research on Pompe disease at Erasmus MC is financially supported by ZonMw- the Netherlands Organization for Health Research and Development [project no. 152001005]; the Dutch TI Pharma initiative "Sustainable Orphan Drug Development through Registries and Monitoring (T6-208): "EUCLYD-a European Consortium for Lysosomal Storage Diseases" (health F2/2008 grant agreement 201678); and the Prinses Beatrix Fonds [project no. OP07-08]; MEUSIX [FP7/2007-2013, grant agreement n 304999]; SSWO; Colciencias and Genzyme Corp. AvdP has provided consultancy services for various industries. RHL is supported by the National Institute for Health Research University College London Hospitals Biomedical Research Centre and had honoraria from Genzyme Corp.

\section{Authors' contributions}

JCvdM and ClvC participated in the recruitment of patients, data collection, analyses, data interpretation, and drafting and revising the manuscript for important intellectual content. ATvdP participated in the coordination, recruitment of patients, data collection, data interpretation, and revising the manuscript for important intellectual content. The other authors participated in the recruitment of patients and/or data collection, and drafting and revising the manuscript for important intellectual content. All authors read and approved the final manuscript.

\section{Acknowledgements}

We would like to thank the patients and the parents for participating in the study, Irene Mavridou for her contribution to the study, and David Alexander for his critical reading of the manuscript.

\section{Author details}

${ }^{1}$ Pompe Center and Center for Lysosomal and Metabolic Diseases, Erasmus MC University Medical Center, Room Sb-1629, P.O. BOX 20603000 CB Rotterdam, The Netherlands. ${ }^{2}$ Centre for Metabolic Disease, University Hospital Gasthuisberg, KU Leuven, Leuven, Belgium. ${ }^{3}$ Department of Pediatrics, Hospital "Dritter Orden", Munich, Germany. "NIHR Biomedical Research Centre, UCL Institute of Child Health and Great Ormond Street Hospital, London, UK. ${ }^{5}$ Division of Metabolic Diseases, Beatrix Children's Hospital, University of Groningen, University Medical Center Groningen, Groningen, The Netherlands. ${ }^{6}$ Department of Pediatrics and Laboratory Genetic Metabolic Diseases, Maastricht University Medical Center, Maastricht, The Netherlands. ${ }^{7}$ Department of Pediatric Neurology, Radboud University Medical Center, Nijmegen, The Netherlands. ${ }^{8}$ Charles Dent Metabolic Unit at University College London Hospitals, London, UK. ${ }^{9}$ Villa Metabolica, Centre for Pediatric and Adolescent Medicine, Mainz, Germany. ${ }^{10}$ Department of Enzymology and Cellular Function, Institute of Child Health, Aghia Sophia Children's Hospital, Athens, Greece. ${ }^{11}$ Department of Pediatrics, Division of Pediatric Respiratory Medicine, Erasmus MC University Medical Center, Rotterdam, The Netherlands.

Received: 3 March 2016 Accepted: 28 April 2016

Published online: 18 May 2016

\section{References}

1. Hirschhorn R, Reuser AJJ. Glycogen Storage Disease Type II: acid alphaglucosidase (acid maltase) deficiency. In: Scriver CR, Beaudet AL, Valle D, Sly WS, editors. The Metabolic and Molecular Bases of Inherited Disease. New York: McGraw-Hill; 2001. p. 3389-420.

2. Engel AG, Hirschhorn R, Huie ML. Acid maltase deficiency. In: Engel AG, editor. Myology. New York: McGraw-Hill; 2004. p. 1559-86.

3. van der Ploeg AT, Reuser AJ. Pompe's disease. Lancet. 2008;372(9646):1342-53.

4. Pompe JC. Over idiopathische hypertrofie van het hart. Ned Tijdsch Geneesk. 1932;76:304-11.

5. van den Hout HM, Hop W, van Diggelen OP, Smeitink JA, Smit GP, Poll-The BT, Bakker HD, Loonen MC, de Klerk JB, Reuser AJ, et al. The natural course of infantile Pompe's disease: 20 original cases compared with 133 cases from the literature. Pediatrics. 2003;112(2):332-40.

6. Kishnani PS, Hwu WL, Mandel H, Nicolino M, Yong F, Corzo D, InfantileOnset Pompe Disease Natural History Study G. A retrospective, multinational, multicenter study on the natural history of infantile-onset Pompe disease. J Pediatr. 2006;148(5):671-6.

7. Engel AG, Gomez MR, Seybold ME, Lambert EH. The spectrum and diagnosis of acid maltase deficiency. Neurology. 1973;23(1):95-106.

8. Laforet P, Nicolino M, Eymard PB, Puech JP, Caillaud C, Poenaru L, Fardeau M. Juvenile and adult-onset acid maltase deficiency in France: genotypephenotype correlation. Neurology. 2000;55(8):1122-8.

9. Hagemans ML, Winkel LP, Van Doorn PA, Hop WJ, Loonen MC, Reuser AJ, Van der Ploeg AT. Clinical manifestation and natural course of late-onset Pompe's disease in 54 Dutch patients. Brain. 2005;128(Pt 3):671-7.

10. Pellegrini N, Laforet P, Orlikowski D, Pellegrini M, Caillaud C, Eymard B, Raphael JC, Lofaso F. Respiratory insufficiency and limb muscle weakness in adults with Pompe's disease. Eur Respir J. 2005;26(6):1024-31.

11. Winkel LP, Hagemans ML, van Doorn PA, Loonen MC, Hop WJ, Reuser AJ, van der Ploeg AT. The natural course of non-classic Pompe's disease; a review of 225 published cases. J Neurol. 2005;252(8):875-84.

12. Montalvo AL, Bembi B, Donnarumma M, Filocamo M, Parenti G, Rossi M, Merlini L, Buratti E, De Filippi P, Dardis A, et al. Mutation profile of the GAA gene in 40 Italian patients with late onset glycogen storage disease type II. Hum Mutat. 2006;27(10):999-1006.

13. Kroos MA, Pomponio RJ, Hagemans ML, Keulemans JL, Phipps M, DeRiso M, Palmer RE, Ausems MG, Van der Beek NA, Van Diggelen OP, et al. Broad spectrum of Pompe disease in patients with the same c.-32-13T-> G haplotype. Neurology. 2007;68(2):110-5.

14. Muller-Felber W, Horvath R, Gempel K, Podskarbi T, Shin Y, Pongratz D, Walter MC, Baethmann M, Schlotter-Weigel B, Lochmuller H, et al. Late onset Pompe disease: clinical and neurophysiological spectrum of 38 patients including longterm follow-up in 18 patients. Neuromuscul Disord. 2007;17(9-10):698-706.

15. Van der Beek NA, Hagemans ML, Reuser AJ, Hop WC, Van der Ploeg AT, Van Doorn PA, Wokke JH. Rate of disease progression during long-term follow-up of patients with late-onset Pompe disease. Neuromuscul Disord. 2009;19(2): $113-7$. 
16. Wokke JH, Escolar DM, Pestronk A, Jaffe KM, Carter GT, van den Berg LH, Florence JM, Mayhew J, Skrinar A, Corzo D et al. Clinical features of late-onset Pompe disease: a prospective cohort study. Muscle Nerve. 2008;38(4):1236-45.

17. van der Beek NA, van Capelle Cl, van der Velden-van Etten Kl, Hop WC, van den Berg B, Reuser AJ, van Doorn PA, van der Ploeg AT, Stam H. Rate of progression and predictive factors for pulmonary outcome in children and adults with Pompe disease. Mol Genet Metab. 2011;104(1-2):129-36.

18. Slonim AE, Bulone L, Ritz S, Goldberg T, Chen A, Martiniuk F. Identification of two subtypes of infantile acid maltase deficiency. J Pediatr. 2000;137(2):283-5.

19. van der Ploeg RJ, Oosterhuis HJ, Reuvekamp J. Measuring muscle strength. J Neurol. 1984;231(4):200-3.

20. Beenakker EA, van der Hoeven JH, Fock JM, Maurits NM. Reference values of maximum isometric muscle force obtained in 270 children aged 4-16 years by hand-held dynamometry. Neuromuscul Disord. 2001;11(5):441-6.

21. Medical Research Council. Aids to examination of the peripheral nervous system. Memorandum no. 45. London: Her Majesty's Stationary Office; 1978.

22. Miller MR, Hankinson J, Brusasco V, Burgos F, Casaburi R, Coates A, Crapo R, Enright P, van der Grinten CP, Gustafsson P et al. Standardisation of spirometry. Eur Respir J. 2005;26(2):319-38.

23. Quanjer PH, Stanojevic S, Cole TJ, Baur X, Hall GL, Culver BH, Enright PL, Hankinson JL, Ip MS, Zheng J, et al. Multi-ethnic reference values for spirometry for the 3-95-yr age range: the global lung function 2012 equations. Eur Respir J. 2012:40(6):1324-43.

24. van Diggelen OP, Oemardien LF, van der Beek NA, Kroos MA, Wind HK, Voznyi YV, Burke D, Jackson M, Winchester BG, Reuser AJ. Enzyme analysis for Pompe disease in leukocytes; superior results with natural substrate compared with artificial substrates. J Inherit Metab Dis. 2009;32(3):416-23.

25. van Diggelen OP, Zhao H, Kleijer WJ, Janse HC, Poorthuis BJ, van Pelt J, Kamerling JP, Galjaard H. A fluorimetric enzyme assay for the diagnosis of Morquio disease type A (MPS IV A). Clin Chim Acta. 1990;187(2):131-9.

26. Hermans MM, van Leenen D, Kroos MA, Reuser AJ. Mutation detection in glycogen storage-disease type II by RT-PCR and automated sequencing. Biochem Biophys Res Commun. 1997;241(2):414-8.

27. Kroos M, Pomponio RJ, van Vliet L, Palmer RE, Phipps M, Van der Helm R, Halley D, Reuser A, Consortium GAAD. Update of the Pompe disease mutation database with 107 sequence variants and a format for severity rating. Hum Mutat. 2008;29(6):E13-26.

28. van der Beek NA, de Vries JM, Hagemans ML, Hop WC, Kroos MA, Wokke JH, de Visser M, van Engelen BG, Kuks JB, van der Kooi AJ, et al. Clinical features and predictors for disease natural progression in adults with Pompe disease: a nationwide prospective observational study. Orphanet J Rare Dis. 2012;7:88.

29. Mellies U, Ragette R, Schwake C, Baethmann M, Voit T, Teschler H. Sleepdisordered breathing and respiratory failure in acid maltase deficiency. Neurology. 2001;57(7):1290-5.

30. Mellies U, Lofaso F. Pompe disease: a neuromuscular disease with respiratory muscle involvement. Respir Med. 2009;103(4):477-84

31. Bersanini C, Khirani S, Ramirez A, Lofaso F, Aubertin G, Beydon N, Mayer M, Maincent K, Boule M, Fauroux B. Nocturnal hypoxaemia and hypercapnia in children with neuromuscular disorders. Eur Respir J. 2012;39(5):1206-12.

32. Wens SC, van Gelder CM, Kruijshaar ME, de Vries JM, van der Beek NA, Reuser AJ, van Doorn PA, van der Ploeg AT, Brusse E. Phenotypical variation within 22 families with Pompe disease. Orphanet J Rare Dis. 2013;8:182.

33. Zatz M, Marie SK, Cerqueira A, Vainzof M, Pavanello RC, Passos-Bueno MR. The facioscapulohumeral muscular dystrophy (FSHD1) gene affects males more severely and more frequently than females. Am J Med Genet. 1998; 77(2):155-61.

34. Tonini MM, Passos-Bueno MR, Cerqueira A, Matioli SR, Pavanello R, Zatz M. Asymptomatic carriers and gender differences in facioscapulohumeral muscular dystrophy (FSHD). Neuromuscul Disord. 2004;14(1):33-8.

35. Fanin M, Nascimbeni AC, Angelini C. Gender difference in limb-girdle muscular dystrophy: a muscle fiber morphometric study in 101 patients. Clin Neuropathol. 2014;33(3):179-85.

36. Korpela MP, Paetau A, Lofberg MI, Timonen MH, Lamminen AE, Kiuru-Enari SM. A novel mutation of the GAA gene in a Finnish late-onset Pompe disease patient: clinical phenotype and follow-up with enzyme replacement therapy. Muscle Nerve. 2009;40(1):143-8.

37. Hermans MM, De Graaff E, Kroos MA, Mohkamsing S, Eussen BJ, Joosse M, Willemsen R, Kleijer WJ, Oostra BA, Reuser AJ. The effect of a single base pair deletion (delta T525) and a C1634T missense mutation (pro545leu) on the expression of lysosomal alpha-glucosidase in patients with glycogen storage disease type II. Hum Mol Genet. 1994;3(12):2213-8.
38. Carlier RY, Laforet P, Wary C, Mompoint D, Laloui K, Pellegrini N, Annane D, Carlier PG, Orlikowski D. Whole-body muscle MRI in 20 patients suffering from late onset Pompe disease: Involvement patterns. Neuromuscul Disord. 2011:21(11):791-9.

39. Groen WB, Leen WG, Vos AM, Cruysberg JR, van Doorn PA, van Engelen BG. Ptosis as a feature of late-onset glycogenosis type II. Neurology. 2006;67(12):2261-2.

40. Ravaglia S, Bini P, Garaghani KS, Danesino C. Ptosis in Pompe disease: common genetic background in infantile and adult series. J Neuroophthalmol. 2010;30(4):389-90.

41. Roberts M, Kishnani PS, van der Ploeg AT, Muller-Felber W, Merlini L, Prasad S, Case LE. The prevalence and impact of scoliosis in Pompe disease: lessons learned from the Pompe Registry. Mol Genet Metab. 2011;104(4): 574-82.

\section{Submit your next manuscript to BioMed Central and we will help you at every step:}

- We accept pre-submission inquiries

- Our selector tool helps you to find the most relevant journal

- We provide round the clock customer support

- Convenient online submission

- Thorough peer review

- Inclusion in PubMed and all major indexing services

- Maximum visibility for your research

Submit your manuscript at www.biomedcentral.com/submit
C Biomed Central 